\title{
Aa. Vv., «L'autre. Cliniques, cultures et sociétés. Revue transculturelle»
}

\section{Paola Ghinelli}

\section{Q OpenEdition}

1 Journals

\section{Édition électronique}

URL : https://journals.openedition.org/studifrancesi/41350

DOI : $10.4000 /$ studifrancesi. 41350

ISSN : 2421-5856

Éditeur

Rosenberg \& Sellier

\section{Édition imprimée}

Date de publication : 1 juillet 2004

Pagination : 228-229

ISSN : 0039-2944

\section{Référence électronique}

Paola Ghinelli, «Aa. VV., «L'autre. Cliniques, cultures et sociétés. Revue transculturelle» », Studi Francesi

[En ligne], 142 (XLVIII | I) | 2004, mis en ligne le 30 novembre 2015, consulté le 09 septembre 2021.

URL : http://journals.openedition.org/studifrancesi/41350 ; DOI : https://doi.org/10.4000/

studifrancesi. 41350

Ce document a été généré automatiquement le 9 septembre 2021.

\section{(c)}

Studi Francesi è distribuita con Licenza Creative Commons Attribuzione - Non commerciale - Non opere derivate 4.0 Internazionale. 


\title{
Aa. Vv., «L'autre. Cliniques, cultures et sociétés. Revue transculturelle»
}

\author{
Paola Ghinelli
}

\section{RÉFÉRENCE}

«L'autre. Cliniques, cultures et sociétés. Revue transculturelle», Dossier Psychiatrie coloniale, 2002 , vol.3, $n^{\circ} 3$, pp. 411-480.

1 La revue transculturelle L'autre doit son nom, entre autres, à la tentative d'établir un rapport entre les sciences cliniques et les sciences humaines pour mieux éclairer les aspects culturels et sociaux de la psychopathologie. Le dernier des trois volumes parus en 2002 est presque entièrement consacré à un dossier sur la psychiatrie coloniale, qui relève d'un grand intérêt pour tout chercheur qui approche de thèmes postcoloniaux, en toute discipline. Lorsqu'ils ne décrivent pas des aspects importants des sociétés postcoloniales, souvent passés sous silence par les études monodisciplinaires, ces articles suggèrent des perspectives méthodologiques intéressantes, dont l'appréciation est facilitée par les résumés en trois langues qui suivent chaque article. L'actualité de ce dossier est mise en valeur par l'éditorial, qui rappelle l'importance d'étudier l'histoire coloniale pour comprendre des phénomènes contemporains.

2 Le premier article constituant le dossier est un hommage à Henri Collomb, le fondateur d'une école de psychiatrie au Sénégal qui approchait la folie de manière anthropologique, en opérant une synergie entre les méthodes locales et les méthodes françaises. Or, en retraçant le parcours humain et scientifique de ce psychiatre, l'article synthétise ses réflexions sur les rapports entre l'aliénation propre à la folie et celle qui découle de la situation coloniale qui le portèrent à adopter une vision de la folie comme maladie sociale. L'article et sa bibliographie constituent aussi un précieux point de départ pour l'étude du rôle de la folie au sein de la société sénégalaise, en contexte colonial et postcolonial. 
3 L'article suivant, de Leslie Swartz, est consacré au rapport entre la psychiatrie et les débats concernant la race et le savoir en Afrique du Sud. Dans ce cas aussi, il est important, pour une approche à la culture de ce pays, de connaître la persistance des préjugés raciaux, et surtout de l'ampleur des conséquences qu'ils peuvent entraîner.

4 Honoré Moustache présente un article qui, quoique consacré aux Antilles, peut se révéler intéressant pour éclairer les rapports entre la psychiatrie occidentale et la culture des pays ex-colonisés. En effet, l'auteur montre, en citant deux cas de patientes d'origine haïtienne ayant un diagnostic d'hystérie, que l'éventail des possibilités offertes aux individus par la société où ils évoluent est déterminant pour la définition du pathologique. En particulier, l'auteur analyse les crises de possession vaudouesques en les comparant aux manifestations hystériques. Dans le cas des Antilles, la connaissance des normes sociales serait souvent sous-estimée par un corps médical qui est essentiellement métropolitain, à cause de la persistance des équilibres coloniaux, et porterait à l'amalgame erronée entre le biographique et le typique en contexte thérapeutique. Le professeur Moustache souhaite l'adoption des suggestions de la psychiatrie comparée pour contraster ces pratiques erronées. Cet article présente aussi le vaudou de manière accessible mais non simpliste.

5 L'article de Albert Diefenbacher consacré à l'histoire d'un asile d'aliénés construit dans l'actuelle Tanzanie par une société missionnaire au début du vingtième siècle et à la description des techniques thérapeutiques mises en acte par les missionnaires, a peut être une visée plus ponctuelle, mais peut se révéler intéressant pour la connaissance de la place de la folie au sein d'une société coloniale.

$6 \quad$ Le dernier article du dossier est une tentative d'analyse de l'histoire de la psychiatrie coloniale française à travers une étude du cas sénégalais. Cela offre à René Collignon l'opportunité de décrire le Sénégal sous le regard français, et de souhaiter un renouveau des études historiques sur l'Afrique qui se fonderait sur l'interdisciplinarité, notamment sur les résultats des Subaltern Studies, et sur l'attention aux documents non publiés.

7 Outre ce dossier, ce numéro de la revue présente d'autres articles dont l'intérêt n'est pas exclusivement clinique. Je cite, entre autres, l'article de Lucette Labache sur les rapports entre Réunionnais et «Zoreils» que l'auteur interprète comme une situation de néocolonialisme en montrant, entre autres, la connaissance des travaux de Memmi, Fanon et Glissant concernant les complexes liés à la colonisation. Remarquons enfin que la définition de rituel que donne Michael Houseman dans son article, nous semble particulièrement digne d'intérêt.

8 Chaque discipline montre des limites dans l'étude des réalités néocoloniales ou excolonisées, attribuables à l'histoire même des disciplines, dont les fondements ont souvent été donnés en pleine période coloniale. Ce numéro de L'autre se veut une tentative de dépassement empirique de ces limites par le biais de l'interdisciplinarité, et pour cela il peut intéresser des chercheurs s'occupant de domaines différents et soucieux d'améliorer la scientificité de leur travail. 